\title{
The synthetic liver $X$ receptor agonist $G W 3965$ reduces tissue factor production and inflammatory responses in human islets in vitro
}

\author{
H. Scholz • T. Lund • M. K. Dahle • J. L. Collins • \\ O. Korsgren • J. E. Wang • A. Foss
}

Received: 3 February 2009 /Accepted: 16 March 2009 /Published online: 5 May 2009

(C) Springer-Verlag 2009

\begin{abstract}
Aims/hypothesis Optimising islet culture conditions may be one strategy for reducing islet loss prior to, and immediately after, islet transplantation. Liver X receptor (LXR) agonism has previously been shown to increase insulin release from pancreatic islets and reduce inflammation in leucocytes. Our aim was to investigate whether the synthetic LXR agonist GW3965 could modulate the inflammatory status of human pancreatic islets.

Methods Levels of pro-inflammatory cytokines and tissue factor in isolated human islets were determined by TaqMan low density array and/or real-time quantitative RT-PCR (mRNA levels) and enzyme immunoassay (EIA) (protein levels). Islet viability was measured using intracellular ATP content, ADP/ATP ratio, mitochondrial dehydrogenase activity (XTT assay) and insulin secretion in a dynamic glucose-challenge model. Apoptosis was determined by EIA measurement of histone-DNA complexes present in cytoplasm and by assaying caspase-3/-7 activity.
\end{abstract}

H. Scholz $(\bowtie) \cdot$ T. Lund $\cdot$ M. K. Dahle $\cdot$ J. E. Wang $\cdot$ A. Foss

Institute for Surgical Research, Oslo University Hospital,

Sognsvannsveien 20,

0027 Oslo, Norway

e-mail: hanne.scholz@medisin.uio.no

H. Scholz $\cdot$ T. Lund $\cdot$ A. Foss

Division of Surgery, Section of Transplantation,

Oslo University Hospital,

Oslo, Norway

J. L. Collins

GlaxoSmithKline Research and Development,

Research Triangle Park, NC, USA

O. Korsgren

Department of Clinical Immunology, Rudbeck Laboratory,

Uppsala University Hospital,

Uppsala, Sweden
Results Treatment of LPS-stimulated human islets with the synthetic LXR agonist GW3965 $(1 \mu \mathrm{mol} / \mathrm{l})$ for $24 \mathrm{~h}$ reduced mRNA and protein levels of selected proinflammatory cytokines (IL-8, monocyte chemotactic protein-1 and tissue factor). Moreover, GW3965 had no adverse effect on insulin secretion, islet viability or apoptosis. No excess of lipid accumulation could be detected with the dosage and exposure time used.

Conclusions/interpretation LXR activation suppresses inflammation in human islets in vitro without adverse effects on islet viability. Short-term moderate activation of LXR prior to islet transplantation may represent a possible strategy for improving post-transplant islet survival.

Keywords Chemokines · Cytokines · GW3965 - Human islets · Inflammatory mediators · Liver X receptor .

Tissue factor

$\begin{array}{ll}\text { Abbreviations } \\ \text { ANGPT1 } & \text { Angiopoietin 1 } \\ \text { LPS } & \text { Lipopolysaccharide } \\ \text { LXR } & \text { Liver X receptor } \\ \text { MCP-1 } & \text { Monocyte chemotactic protein-1 } \\ \text { qRT-PCR } & \text { Quantitative RT-PCR } \\ \text { SREBP } & \text { Sterol regulatory element-binding protein } \\ \text { TF } & \text { Tissue factor } \\ \text { TLDA } & \text { TaqMan low density array } \\ \text { VEGF } & \text { Vascular endothelial growth factor }\end{array}$

Introduction

Transplantation of pancreatic islets is currently a treatment option for repeated severe hypoglycaemia in type 1 diabetes 
mellitus and, as such, the therapy is highly efficient. However, sustained insulin-independence after islet transplantation has been difficult to achieve [1], partly because of a significant loss of islets during brain death, islet isolation, transplantation and revascularisation in the liver $[2,3]$. Islet apoptosis may be induced by various stress factors such as hypoxia [4] and inflammation [5]. Optimising islet culture conditions may be one way to reduce islet loss prior to, and immediately after, islet transplantation.

Liver $\mathrm{X}$ receptors $(\operatorname{LXR} \alpha / \beta)$, also known as nuclear receptor subfamily 1 , group $\mathrm{H}$, member 3 (NR1H3) and nuclear receptor subfamily 1 , group $\mathrm{H}$, member 2 (NR1H2), respectively, are ligand-activated transcription factors that belong to the nuclear receptor superfamily, the members of which act as key regulators of lipid metabolism and inflammation (reviewed in [6]). Several studies have suggested a role for LXRs in inflammatory diseases such as atherosclerosis [7], Alzheimer's disease [8] and stroke [9]. In addition, in vivo and in vitro studies have demonstrated that activation of LXR agonists antagonises inflammatory gene expression in mouse macrophages [10], microglia and astrocytes [11], and human monocytes [12]. In cultured murine and human macrophages the synthetic LXR agonist GW3965 has been shown to reduce cytokine-induced tissue factor (TF) production [13] and we have previously shown that GW3965 dose-dependently attenuated LPS-induced release of TNF- $\alpha$ and prostaglandin $E_{2}$ by hepatic Kupffer cells in vitro as well as in vivo [14]. Human islets exposed to human blood trigger an instant blood-mediated inflammatory reaction, characterised by platelet consumption and activation of the coagulation and complement systems, and this activation may impair engraftment after intraportal islet transplantation [15].

Tissue factor produced by islets is considered to activate this process and the clinical outcome of islet transplantation is directly related to the extent of TF production [16].
In this early post-transplantation phase, up to $70 \%$ of islet mass could be lost in clinical allo-transplantation [17]. Although the pathological and clinical significance of the effects of LXR agonists on insulin-producing cells remains controversial, to date there is no information on the impact of LXR activation on the inflammatory status in human islets. Hence, the aim of this study was to determine the effect of the synthetic LXR agonist GW3965 on TF production and the inflammatory responses in human islets. In the present study, we demonstrate that activation of LXR in vitro decreases $T F$ (also known as F3) expression and suppresses production of pro-inflammatory cytokines in human islets without adverse effects on islet viability.

\section{Methods}

Treatment of cultured islets with GW3965, methylprednisolone (MP) and LPS

GW3965 provided by GlaxoSmithKline, is an synthetic LXR agonist that does not discriminate between LXR $\alpha$ and LXR $\beta$ [18], was dissolved in DMSO (0.01\%, wt/vol.). Cultured human islets were treated with GW3965, $1 \mu \mathrm{mol} /$ 1, methylprednisolone (SoluMedrol, Pfizer, New York, USA), $1 \mu \mathrm{g} / \mathrm{ml}$, or the DMSO 'vehicle' only (control) for $24 \mathrm{~h}$, and with lipopolysaccharide (LPS, $1 \mu \mathrm{g} / \mathrm{ml}$ ) (serotype 0111:B4, Sigma-Aldrich, Sigma, St Louis, MO, USA) for the last $6 \mathrm{~h}$ where indicated.

\section{Islet isolation}

Islets were isolated according to the automated method as previously described [19] in the Central Laboratory of the Nordic Network for Clinical Islet Transplantation in
Table 1 Donor and islet preparation characteristics

IEQ, islet equivalents

\begin{tabular}{|c|c|c|c|c|c|}
\hline Donor pancreas & 1 & 2 & 3 & 4 & 5 \\
\hline Age (years) & 46 & 54 & 55 & 56 & 77 \\
\hline Sex & Female & Male & Female & Female & Female \\
\hline Cold ischaemia time (h) & 12.3 & 3.5 & 13 & 6.3 & 12.5 \\
\hline BMI $\left(\mathrm{kg} / \mathrm{m}^{2}\right)$ & 24 & 29 & 22 & 27 & 21 \\
\hline Pancreas weight (g) & 93 & 133 & 95 & 122 & 90 \\
\hline Yield (IEQ) & 83,600 & 220,000 & 388,000 & 335,000 & 195,000 \\
\hline Purity of fractions used (\%) & 50 and 65 & 85 and 90 & 95 & 90 and 95 & 50 and 75 \\
\hline Insulin/DNA content (ng/ml) & 7.1 & 6.9 & 1.5 & 5.4 & 6.1 \\
\hline Insulin stimulation index (SI) & 6.1 & 3.4 & 9.3 & 12 & 6.1 \\
\hline $\mathrm{ADP} / \mathrm{ATP}$ ratio & 0.2 & 0.19 & 0.07 & $<0.05$ & $<0.05$ \\
\hline TF content $(\mathrm{pmol} / / \mu \mathrm{g}$ DNA) & 0.025 & 0.009 & 0.027 & 0.022 & 0.049 \\
\hline 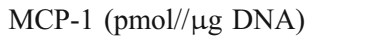 & 0.004 & 0.011 & 0.006 & 0.002 & 0.012 \\
\hline IL-8 (pmol/ $/ \mu \mathrm{g}$ DNA) & 0.013 & 0.038 & 0.014 & 0.008 & 0.058 \\
\hline
\end{tabular}


Uppsala, Sweden. Donor and islet characteristics are presented in Table 1.

Measurements of insulin secretion by dynamic challenge with glucose

Insulin secretion in response to glucose stimulation was assessed in a dynamic perfusion system. Twenty islets were hand-picked and photographed under a microscope, and initially perfused with $1.67 \mathrm{mmol} / \mathrm{l}$ glucose, then with $20 \mathrm{mmol} / \mathrm{l}$, and then again with $1.67 \mathrm{mmol} / \mathrm{l}$. During the $120 \mathrm{~min}$ perfusion, fractions were collected at $6 \mathrm{~min}$ intervals, immediately ice chilled and stored at $-20^{\circ} \mathrm{C}$ until analysed. Thereafter, the pictures of the different islet preparations were analysed with Cellimage (Friberg, Uppsala, Sweden), total islet size calculated and insulin secretion normalised to pmol $1^{-1}$ insulin 100 islet equivalents $^{-1}$.

Enzyme immunoassays

Levels of IL-8, monocyte chemotactic protein-1 (MCP-1) (R\&D Systems, Minneapolis, MN, USA), TF (Imubind, American Diagnostic, Greenwich, CT, USA), and insulin (Mercodia Insulin ELISA, Uppsala, Sweden) were measured using enzyme immunoassays (EIA) according to manufacturer's instructions. Total protein was measured using standard bicinchoninic acid (BCA) protein assay (Pierce, Rockford, IL, USA).

Gene expression analysis

Total RNA was isolated from frozen islet pellets with the RNA Isolation Kit - High Performance and the MagNA Pure LC instrument (Roche Applied Science, Indianapolis, IN, USA) according to the manufacturer's instructions, and was stored at $-80^{\circ} \mathrm{C}$. The amount of RNA in all samples was quantitated using a NanoDrop ND-1000 UV/Vis spectrophotometer (Saveen Werner, Malmö, Sweden). Using the High-Capacity cDNA Archive Kit as per the manufacturer's instructions (Applied Biosystems, Foster City, CA, USA), $1 \mu \mathrm{g}$ total RNA was reverse-transcribed.

TaqMan low density array The use of a TaqMan low density array (TLDA) custom-designed format with a $47+1$ $(G A P D H)$ configuration (Table 2) from Applied Biosystems was based on our interest in gene expression regulation that, from the literature, appeared to be involved in coagulation, inflammation and apoptosis. A total of $100 \mu \mathrm{l}$ reaction mixture with $5 \mu \mathrm{l}$ cDNA template (100 ng mRNA) and $50 \mu 12 \times$ TaqMan Universal PCR Master Mix (Applied Biosystems) was added to each line of reaction wells after vortex and brief centrifugation. Each reaction well contained $1 \mu 1$ reaction mixture with $1 \mathrm{ng}$ mRNA. Array cards were sealed with a TaqMan low density array sealer (Applied Biosystems) before centrifugation in a Sorvall Legend centrifuge (Kendro Scientific, Asheville, $\mathrm{NC}$, USA) for $1 \mathrm{~min} \times 2$ at $12,000 \mathrm{rpm}$. The PCR amplifications were done in the micro-fluidic card sample block of an ABI Prism 7900HT sequence detection system (Applied Biosystems). The amplification protocol was: $2 \mathrm{~min}$ at $50^{\circ} \mathrm{C}$ to activate uracil-DNA glycosylase, $10 \mathrm{~min}$ at $94.5^{\circ} \mathrm{C}$ (activation), 40 cycles of denaturation at $97^{\circ} \mathrm{C}$ for $30 \mathrm{~s}$, and annealing and extension at $59.7^{\circ} \mathrm{C}$ for $1 \mathrm{~min}$. All experiments were analysed on array cards with the same batch number. The relative amount of each target gene mRNA to $G A P D H$ was calculated as difference in threshold cycle number $\left(C_{\mathrm{t}}\right), \Delta C_{\mathrm{t}}=C_{\mathrm{t}}$ Target $-C_{\mathrm{t}} G A P D H$. The threshold cycle $C_{\mathrm{t}}$ was automatically given by the SDS2.2 software package (Applied Biosystems) and $C_{\mathrm{t}}$ values above 35 were considered absent. The mRNA expression levels of GW39865-exposed islets and control islets were displayed as three groups; high $\left(\Delta C_{\mathrm{t}}<2\right)$, medium $\left(\Delta C_{\mathrm{t}} 2-8\right)$ and low $\left(\Delta C_{\mathrm{t}}>8\right)$. For the calculation of the differential expression in GW3965-exposed islets compared with controls, the $\Delta C_{\mathrm{t}}$ value for GW3965exposed islets was divided by $\Delta C_{\mathrm{t}}$-value for controls. Trends obtained were used for targeted real-time quantitative RT-PCR (qRT-PCR).

\section{Real-time quantitative RT-PCR}

Real-time qRT-PCR using sequence-specific primers was performed on an ABI Prism 7900HT sequence detector (Applied Biosystems) using 2× qPCR Master Mix for SYBR Green (Eurogentec, Liege, Belgium), $300 \mathrm{nmol} /$ 1 sense and antisense primers, $2.5 \mu \mathrm{l}$ cDNA template (100 ng mRNA), and water to bring the volume to $25 \mu 1$. The specificities of all SYBR Green assays were confirmed by melting-point analysis. Levels of GAPDH mRNA were used for normalisation of target-gene expression. All samples were run in duplicate using the following primers: GAPDH: forward 5'-CCAAGGTCATCCATGACAACTT3', reverse 5'-AGGGGCCATCCACAGTCTT-3'; $L X R-\alpha$ (also known as NR1H3): forward 5'-TCAGCATCTTCTCTGCA GACCGG-3', reverse 5'-TCATTAGCATCCGTGGGAACA; $L X R-\beta$ (also known as NR1H2): forward 5'-CTGCTAGAGA CAGCCAGGC, reverse 5'-AAGATGTTGATGGCGATGAG; $A B C A 1$ : forward 5'-GGTGTCAAACAGCATCATGG, reverse 5'-CTCCAGGGGAAATGTCAGAA; $A B C G 1$ : forward 5'-GACTCGGTCCTGACACACCT, reverse 5' CTCCAGGGGAAATGTCAGAA; SREBP-1c (also known as $S R E B F 1$ ): forward 5'-GGAGGGGTAGGGCCAAC, reverse 5'-GTCAAATAGGCCAGGGAAGTC; TF: forward 5'-GCGCTTCAGGCACTACAAAT-3', reverse 5'- 
Table 2 Effect of LXR agonist on islet gene expression and regulation in a TaqMan low density array

\begin{tabular}{|c|c|c|c|c|c|}
\hline \multirow[t]{2}{*}{ Gene } & \multirow[t]{2}{*}{ Assay ID } & \multirow[t]{2}{*}{ Mean expression level } & \multicolumn{3}{|c|}{$\Delta C_{\mathrm{t}} \mathrm{GW} 3965 / \Delta C_{\mathrm{t}}$ control } \\
\hline & & & Mean & $\mathrm{SD}$ & $p$ value \\
\hline \multicolumn{6}{|c|}{ Genes that tended to be downregulated by GW3965 } \\
\hline IL8 & Hs00174103_m1 & High & 1.30 & 0.36 & $0.05^{*}$ \\
\hline$G C G$ & Hs00174967_m1 & High & 1.01 & 0.04 & 0.75 \\
\hline STAT1 & Hs00234829_m1 & Medium & 1.16 & 0.15 & $0.02^{*}$ \\
\hline NFKB1 & Hs00765730_m1 & Medium & 1.00 & 0.07 & 0.90 \\
\hline ICAMI & Hs00164932_m1 & Medium & 1.24 & 0.09 & 0.06 \\
\hline$M C P-1$ & Hs00234140_m1 & Medium & 1.18 & 0.13 & $0.01^{* *}$ \\
\hline SMAD3 & Hs00232222_m1 & Medium & 1.03 & 0.08 & 0.32 \\
\hline$E G F R$ & Hs00193306_m1 & Medium & 1.01 & 0.05 & 0.75 \\
\hline$I L 1 B$ & Hs00174097_m1 & Medium & 1.01 & 0.04 & 0.61 \\
\hline$T G F B 1$ & Hs99999918_m1 & Medium & 1.01 & 0.67 & 0.66 \\
\hline CASP8 & Hs00154256_m1 & Low & 1.02 & 0.04 & 0.21 \\
\hline$T N F$ & Hs00174128_m1 & Low & 1.00 & 0.03 & 0.69 \\
\hline CCL3 & Hs00234142_m1 & Low & 1.01 & 0.06 & 0.76 \\
\hline CCL5 & Hs00174575_m1 & Low & 1.17 & 0.14 & $0.01^{* *}$ \\
\hline$J A K 1$ & Hs00233820_m1 & Low & 1.05 & 0.12 & 0.29 \\
\hline SLC30A10 & Hs00218883_m1 & Low & 1.01 & 0.05 & 0.62 \\
\hline$C 5$ & Hs00156197_m1 & Low & 1.00 & 0.04 & 0.84 \\
\hline IL6 & Hs00174131_m1 & Low & 1.22 & 0.37 & 0.13 \\
\hline$B C L 2$ & Hs00153350_m1 & Low & 1.08 & 0.12 & 0.10 \\
\hline IL10 & Hs00174086_m1 & Low & 1.00 & 0.10 & 0.57 \\
\hline \multicolumn{6}{|c|}{ Genes that tended to be upregulated by GW3965 } \\
\hline INS & Hs02741908_m1 & High & 0.98 & 0.05 & 0.78 \\
\hline TLR4 & Hs00152939_m1 & Medium & 0.86 & 0.11 & $0.03^{*}$ \\
\hline$D I A B L O$ & Hs00219876_m1 & Medium & 0.99 & 0.08 & 0.71 \\
\hline$C D 40$ & Hs00386848_m1 & Medium & 0.99 & 0.08 & 0.71 \\
\hline SLC39A1 & Hs00205358_m1 & Medium & 0.69 & 0.13 & $0.002^{* *}$ \\
\hline$B A X$ & Hs00180269_m1 & Medium & 0.99 & 0.12 & 0.81 \\
\hline$A C T B$ & Hs99999903_m1 & Medium & 0.49 & 0.19 & $0.001^{* *}$ \\
\hline INSR & Hs00169631_m1 & Medium & 0.94 & 0.09 & 0.10 \\
\hline$V E G F A$ & Hs00900054_m1 & Medium & 0.91 & 0.11 & $0.05^{*}$ \\
\hline$T X N I P$ & Hs00197750_m1 & Medium & 0.94 & 0.25 & 0.53 \\
\hline$M A P K 1$ & Hs00177066_m1 & Medium & 0.81 & 0.32 & 0.14 \\
\hline CCL4 & Hs99999148_m1 & Medium & 0.98 & 0.27 & 0.87 \\
\hline CXCL10 & Hs00171042_m1 & Low & 0.78 & 0.25 & $0.05^{*}$ \\
\hline$B A D$ & Hs00188930_m1 & Low & 0.95 & 0.07 & 0.06 \\
\hline IL15 & Hs00542562_m1 & Low & 0.91 & 0.12 & 0.07 \\
\hline FOXP3 & Hs00203958_m1 & Low & 0.91 & 0.12 & 0.07 \\
\hline CCR5 & Hs00152917_m1 & Low & 0.95 & 0.09 & 0.38 \\
\hline SSTR5 & Hs00265647_s1 & Low & 0.98 & 0.12 & 0.66 \\
\hline$A N G P T 1$ & Hs00181613_m1 & Low & 0.77 & 0.12 & $0.001^{* *}$ \\
\hline CASP3 & Hs00234385_m1 & Low & 0.96 & 0.05 & 0.07 \\
\hline CXCL12 & Hs00930455_m1 & Low & 0.99 & 0.07 & 0.63 \\
\hline IL18 & Hs00155517_m1 & Low & 0.88 & 0.24 & 0.20 \\
\hline$F A S$ & Hs00163653_m1 & Low & 0.97 & 0.20 & 0.70 \\
\hline CASP9 & Hs00154261_m1 & Low & 0.89 & 0.13 & 0.06 \\
\hline
\end{tabular}


Table 2 (continued)

\begin{tabular}{|c|c|c|c|c|c|}
\hline \multirow[t]{2}{*}{ Gene } & \multirow[t]{2}{*}{ Assay ID } & \multirow[t]{2}{*}{ Mean expression level } & \multicolumn{3}{|c|}{$\Delta C_{\mathrm{t}} \mathrm{GW} 3965 / \Delta C_{\mathrm{t}}$ control } \\
\hline & & & Mean & $\mathrm{SD}$ & $p$ value \\
\hline \multicolumn{6}{|c|}{ Genes that were not expressed } \\
\hline$C C R 2$ & Hs00174150_m1 & - & - & - & - \\
\hline IL4 & Hs00174122_m1 & - & - & - & - \\
\hline$I F N G$ & Hs00174143_m1 & - & - & - & - \\
\hline
\end{tabular}

Data are mean $\pm \mathrm{SD}$

Expression levels are based on the individual $\Delta \mathrm{C}_{\mathrm{t}}$ values, denoted as high, medium and low as described in the methods section. No expression is shown as -

Six different fractions from three independent donors were tested, with purity ranging from $90 \%$ to $95 \%$

Significant differences compared with the vehicle group: ${ }^{*} p<0.05,{ }^{* *} p<0.01$

TTTGCTTTTCCAATCTCCTGA-3'; IL8: forward 5'GCCAACACAGAAATTATTGTAAAGCTT-3', reverse 5'CCTCTGCACCCAGTTTTCCTT-3'; and $M C P-1$ (also known as CCL2): forward 5'-AAGCTGTGATCTTCAA GACCATTGT-3', reverse 5'-TGGAATCCTGAACC CACTTCTG-3'. Standard curves were run on the same plate, and the standard curve method was used to calculate the relative gene expression.

Lipid staining (Oil-Red-O) and lipid-mass quantification

One hundred hand-picked islets were incubated with or without test compounds for $24 \mathrm{~h}$. After incubation, islets were washed once in ice-cold PBS, which was followed by formaldehyde fixation (2\% in PBS) for $30 \mathrm{~min}$ at room temperature. Neutral lipids were stained using $0.5 \%$ Oil-Red$\mathrm{O}$ (Sigma) in isopropanol for $60 \mathrm{~min}$. The Oil-Red-O-stained lipids were measured spectrophotometrically after isopropanol extraction, or morphologically evaluated by microscopy. In parallel experiments cellular content of total cholesterol and triacylglycerols was measured colorimetrically by an enzymatic assay (BioMérieux, Marcy-l'Etoile, France) after hexane-isopropanol extraction of 100 hand-picked islets.

Assessment of islet viability and purity

Mitochondrial function Cell viability was assessed using a combination of the ATP luminescence-based assay CellTiterGlo (Promega, Mannheim, Germany) for ATP content, and the colorimetric XTT tetrazolium assay (Roche Diagnostics, Mannheim, Germany) for total dehydrogenase activity. The ApoGlow kit (Cambrex Bio Science, Nottingham, UK) was used for ADP/ATP determination according to the manufacturer's instructions as previously described [20]. One hundred hand-picked islets were cultured with or without test compounds for $24 \mathrm{~h}$. Samples prepared as per kit instructions were plated in an opaque-walled plate and placed on an orbital shaker for $2 \mathrm{~min}$, then equilibrated at room temperature for $10 \mathrm{~min}$ and read using a TECAN GENios plate reader with the Magellan version 6.0 software (Tecan Group, Männedorf, Switzerland). Serially diluted ATP (SigmaAldrich) was used as a standard in both the CellTiter-Glo and the ApoGlow assays. In parallel experiments, islets were co-cultured during the last $6 \mathrm{~h}$ with $75 \mu \mathrm{l}$ of XTT-labelling reagent (Boehringer Mannheim, Mannheim, Germany; final concentration $0.3 \mathrm{mg} / \mathrm{ml}$ ). This assay is based on the conversion of the tetrazolium salt XTT into an orange-red coloured formazan product by mitochondrial enzymes. The optical densities were monitored spectrophotometrically at $492 \mathrm{~nm}$ using the TECAN GENios plate reader.

Apoptosis measurement The apoptotic response was measured using Apo-ONE Caspase-3/-7 assay (Promega, Mannheim, Germany) and the Cell Death Detection ELISA $^{\text {PLUS }}$ (Roche Diagnostics, Mannheim, Germany) according to the manufacturer's instructions.

Briefly, 100 hand-picked islets were incubated for $24 \mathrm{~h}$ with or without test compounds. After incubation, islets were washed and transferred into a 96-well plate (20 islets/well) for caspase-3/-7 activity, measured as an increase in the rhodamine 110 fluorescence (excitation $499 \mathrm{~nm}$ and emission $521 \mathrm{~nm}$ ) after cleavage of the caspase substrate Z-DEVDrhodamine, or lysed at room temperature for $30 \mathrm{~min}$ and then transferred into a 96-well plate $(20 \mu \mathrm{l})$, for apoptotic cell death measurement by the detection of DNA-histone complexes present in the cytoplasmic fraction of cells. Absorbance of samples was read spectrophotometrically at $405 \mathrm{~nm}$ using the TECAN GENios plate reader.

\section{Statistical analysis}

The data in Table 2 are expressed as mean $\pm \mathrm{SD}$, whereas all other data are expressed as mean \pm SEM. Statistical signif- 
icance was determined using a one-way ANOVA with a post hoc Bonferroni's test or Student's $t$ test. Differences were considered significant when $p<0.05$.

\section{Results}

LXRs are produced in human pancreatic islets: effect of LPS, GW3965 and methylprednisolone on expression levels

Real-time qRT-PCR analysis showed that LXR- $\alpha$ and $-\beta$ were produced in human islets at similar levels, and the production of LXRs in islets was compared with that in human monocytes, where LXR production is documented [12] (Fig. 1a, b). Additionally, exposure to LPS (1 $\mu \mathrm{g} / \mathrm{ml}$, duration $6 \mathrm{~h}$ ) resulted in a significant increase in production of both LXR- $\alpha$ and $-\beta$ in human islets compared with unexposed controls (1.6- and 1.7-fold increase, respectively, $p<0.05$ ) (Fig. 1a, b). Interestingly, addition of the LXR agonist GW3965 (1 $\mu \mathrm{mol} / \mathrm{l}) 18 \mathrm{~h}$ prior to LPS exposure resulted in an additional increase in the expression of $L X R-\alpha$ and $L X R-\beta$ (2.0- and 2.3-fold increase compared with LPS- exposed controls, respectively, $p<0.05$; Fig. 1a, b). Because LXRs have a profound effect on serum glucocorticoid levels and secretion from the adrenal gland [21], we evaluated the effect of glucocorticoids on the expression levels of $L X R-\alpha$ and $L X R-\beta$. However, we found no evidence for an effect of the glucocorticoid methylprednisolone, $1 \mu \mathrm{g} / \mathrm{ml}$, on the expression of these genes in human islets (Fig. 1a, b). These data indicated that LXRs are produced in human islets, and that LPS increases the level of production. Additionally, the data indicate that the LXR agonist GW3965 further upregulated LXR production when measured after $24 \mathrm{~h}$. Glucocorticoids (methylprednisolone), however, did not have an effect on $L X R-\alpha$ and $L X R-\beta$ expression, suggesting that the immunosuppressive effects of glucocorticoids are independent of LXR activation.

\section{Effects of GW3965 on human islet lipid homeostasis}

Next, we evaluated the effect of GW3965 on well-known LXR target genes by real time qRT-PCR. As expected, the LXR agonist GW3965 (1 $\mu \mathrm{mol} / \mathrm{l})$ potently induced the expression of the genes encoding cholesterol efflux trans-
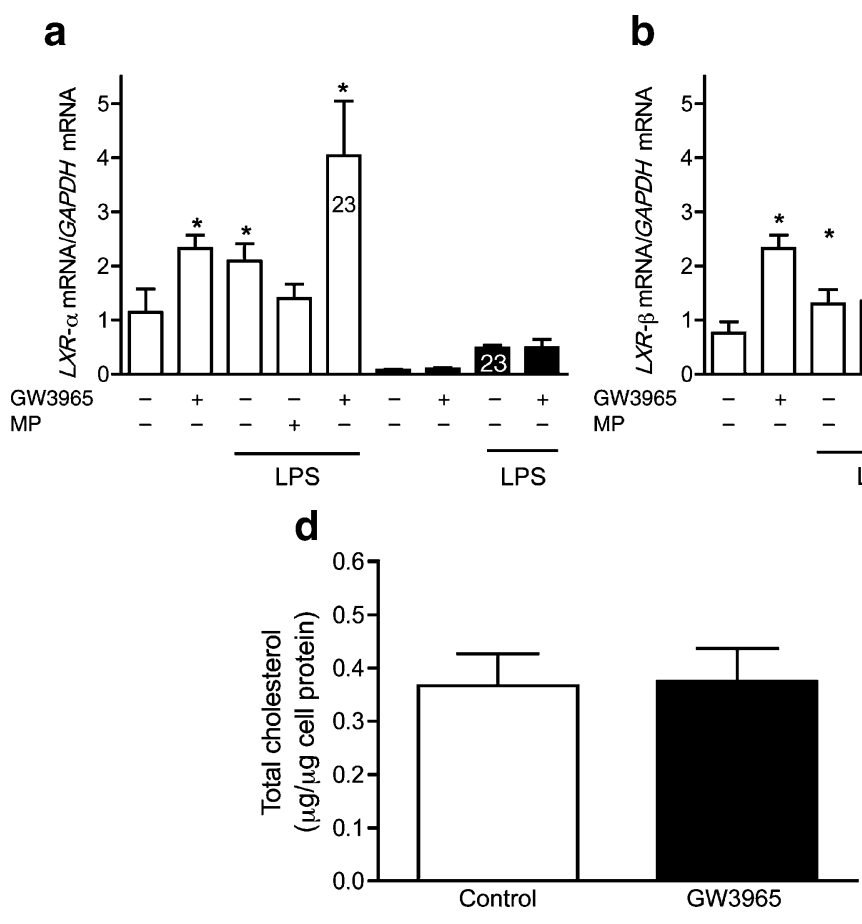

Fig. 1 Effect of LXR agonist on cholesterol homeostasis in human pancreatic islets. Levels of $L X R-\alpha$ (a) and $L X R-\beta$ (b) mRNA from human islets (white bars) treated without or with LXR agonist (GW3965), $1 \mu \mathrm{mol} / \mathrm{l}$, or methylprednisolone, $1 \mu \mathrm{g} / \mathrm{ml}$, for $24 \mathrm{~h}$, and as a positive control from human monocytes (black bars) treated without or with LXR agonist (GW3965), $1 \mu \mathrm{mol} / 1$, for $3 \mathrm{~h}$ were analysed using real-time RTPCR assays and normalised to GAPDH mRNA levels. Where indicated, $1 \mu \mathrm{g} / \mathrm{ml}$ LPS was added to the pancreatic islets at $t=18 \mathrm{~h}$ and to the monocytes at $t=1 \mathrm{~h}$. Cycle times for the highest-expressing group for each gene are shown in their corresponding bar. c Human islets were

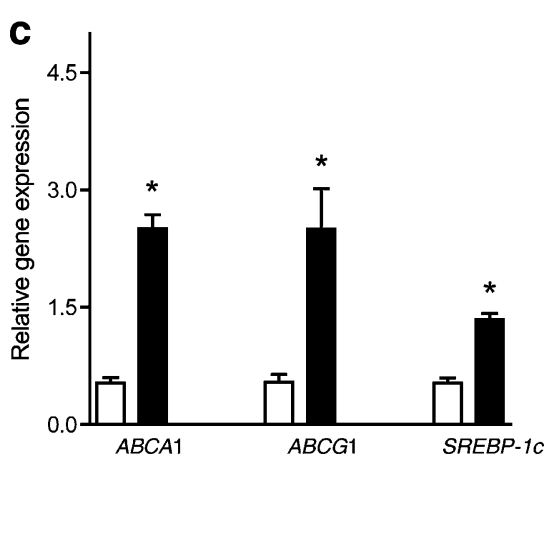

e

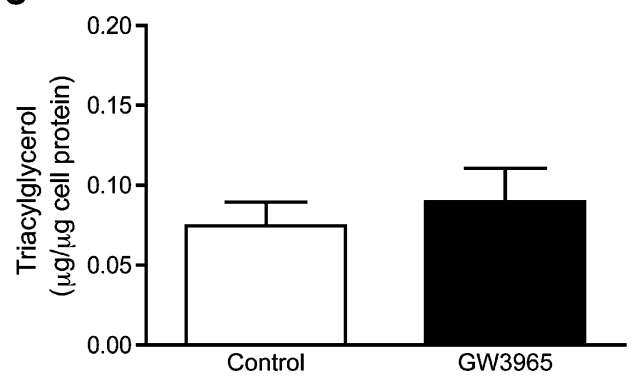

treated without (control, white bars) or with $1 \mu \mathrm{mol} / 1 \mathrm{LXR}$ agonist (GW3965, black bars) for $24 \mathrm{~h}$. RNA was prepared and subjected to realtime qRT-PCR analysis of LXR target genes $A B C A 1, A B C G 1$ and SREBP-1c. The expression levels were normalised to GAPDH levels. Cholesterol (d) and triacylglycerol (e) content normalised to total protein content in human islets after LXR agonist treatment (GW3965), $1 \mu \mathrm{mol} / \mathrm{l}$, or vehicle for $24 \mathrm{~h}$ using EIA as described in the methods section. $n=10$ different fractions from five independent donors, with purity ranging from $50 \%$ to $95 \%$. ${ }^{*} p<0.05$, significantly different from vehicle-treated samples. Data represent the mean \pm SEM. MP, methylprednisolone 
porters ATP-binding cassettes A1 and G1 (ABCA1 and ABCG1) $(p<0.05)$ and the master regulator of fatty acid metabolism, sterol regulatory element-binding protein (SREBP-1c), $(p<0.05)$ in human islets (Fig. 1c). It has been shown that the LXR agonist T0901317 induces severe lipogenesis [22] and that LXR-deficient mice exhibit reduced NEFA levels and improved metabolic control [23]. We therefore examined whether the LXR agonist GW3965 had effects on lipid homeostasis on human islets. We found no evidence of excess cholesterol (Fig. 1d) or triacylglycerol (Fig. 1e) stored in human islets at the concentration used in our experiments. In addition, OilRed-O staining showed no difference in the accumulation of neutral lipids in GW3965-exposed islets compared with control islets (data not shown).

Effect of GW3965 on human islet gene expression in TLDA

We analysed the expression of genes encoding anti- and pro-inflammatory markers, as well as markers associated with islet viability and insulin synthesis, using a TLDA (Table 2) after $24 \mathrm{~h}$ of GW3965 (1 $\mu \mathrm{mol} / \mathrm{l})$ or vehicle exposure. LPS $(1 \mu \mathrm{g} / \mathrm{ml})$ was added at $t=18 \mathrm{~h}$. As shown in Table 2, GW3965 significantly downregulated the expres- sion of genes encoding several pro-inflammatory mediators and cytokines (MCP-1, chemokine [C-C motif] ligand 5 [CCL5] and IL-8) as well as the transcription factor signal transducer and activator of transcription 1 (STAT1). On the other hand, GW3965 upregulated expression of the gene encoding toll-like receptor 4 (TLR4), a receptor mediating the recognition of LPS and an activator of the innate immune system [5]. Expression of the gene encoding proinflammatory cytokine chemokine (C-X-C motif) ligand 10 (CXCL10) was also upregulated, this cytokine having previously been shown to play a role in infection of human islets [24]; however, the expression level was very low and needs to be verified. Of note, the pro-angiogenetic factor angiopoietin 1 (ANGPT1) and vascular endothelial growth factor (VEGF) were upregulated as well as the zinc transporter solute carrier family 39, member 1 (SLC39A1), reported to be produced in MIN6 cells and mouse islets [25]. These data suggest that LXR activation using GW3965 affects the inflammatory profile of human islets.

Effect of GW3965 on key inflammation markers in human islets

Because cytokine-induced islet dysfunction probably plays an important role in islet survival after transplantation [5],
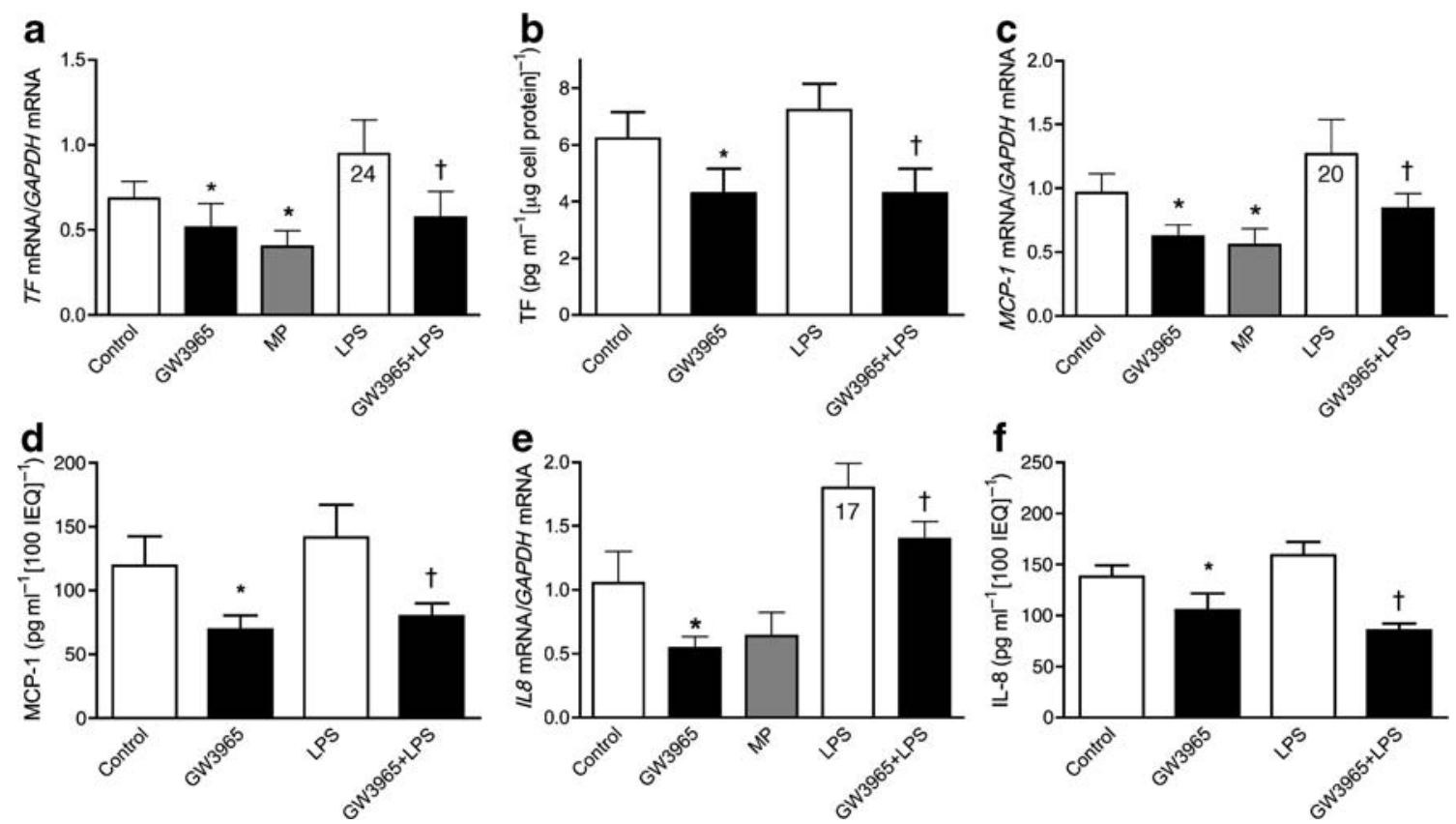

Fig. 2 Effect of LXR agonist on key inflammatory mediators in human pancreatic islets. Islets were treated without or with LXR agonist (GW3965, black bars), $1 \mu \mathrm{mol} / \mathrm{l}$, or methylprednisolone (grey bars), $1 \mu \mathrm{g} / \mathrm{ml}$, for $24 \mathrm{~h}$. Where indicated, $1 \mu \mathrm{g} / \mathrm{ml}$ LPS was added at $t=18 \mathrm{~h}$. Levels of mRNA were analysed using real-time qRT-PCR and normalised to GAPDH mRNA levels. Cycle times for the highestexpressing group for each gene are shown in their corresponding bar. Protein levels were analysed using EIA as described in the methods.
Results for the control, vehicle-treated islets, are shown as white bars. $T F$ mRNA (a) and intracellular of TF protein (b). $M C P-1$ mRNA (c) and MCP-1 protein in the supernatant fraction (d). IL 8 mRNA (e) and IL-8 protein in the supernatant fraction (f). $n=10$ islet preparations from five independent donors, with purity ranging from $50 \%$ to $95 \%$. Data represent the mean \pm SEM. ${ }^{*} p<0.05$, significantly different from control; ${ }^{\dagger} p<0.05$, significantly different from LPS-stimulated control. IEQ, islet equivalents; MP, methylprednisolone 
we chose to further evaluate anti-inflammatory effects of the LXR agonist GW3965 in human islets. Levels of TF and MCP-1 have been shown to correlate with islet posttransplant function [26], and IL8 was the highest expressed gene encoding a pro-inflammatory cytokine in our TLDA (Table 2). Therefore, these three mediators were chosen for further evaluation. Methylprednisolone has been shown to have potent anti-inflammatory properties in human islets [27] and was therefore used as a positive control. As depicted in Fig. 2a-f, islets exposed to GW3965 (1 $\mu \mathrm{mol} / \mathrm{l})$ for $24 \mathrm{~h}$ showed a significantly reduced mRNA expression of $T F$ (Fig. 2a), MCP-1 (Fig. 2c) and IL8 (Fig. 2e) (1.3-, 1.5 - and 1.9-fold reduction, respectively, $p<0.05)$ compared with controls, analysed by real-time qRT-PCR. Similarly, when GW3965-exposed islets were stimulated with LPS $(1 \mu \mathrm{g} / \mathrm{ml})$ at $t=18 \mathrm{~h}$, we found significantly reduced mRNA expression of $T F$ (Fig. 2a), $M C P-1$ (Fig. 2c) and IL8 (Fig. 2e) (1.5-, 2.2- and 2.5-fold reduction, respectively, $p<$ $0.05)$ compared with LPS-stimulated controls. These geneexpression data were confirmed with protein levels, either by measurement of intracellular TF (Fig. 2b) or levels of MCP-1 (Fig. 2d) and IL-8 (Fig. 2f) in the supernatant fractions. As expected, treatment of islets with methylprednisolone for $24 \mathrm{~h}$ significantly reduced mRNA expression of $T F$ (Fig. 2a) and $M C P-1$ (Fig. 2c), but not IL8 (Fig. 2e).

Effect of GW3965 on insulin secretion from human islets

Several immunomodulatory drugs [27-29] have negative effects on insulin secretion from human islets; however, the

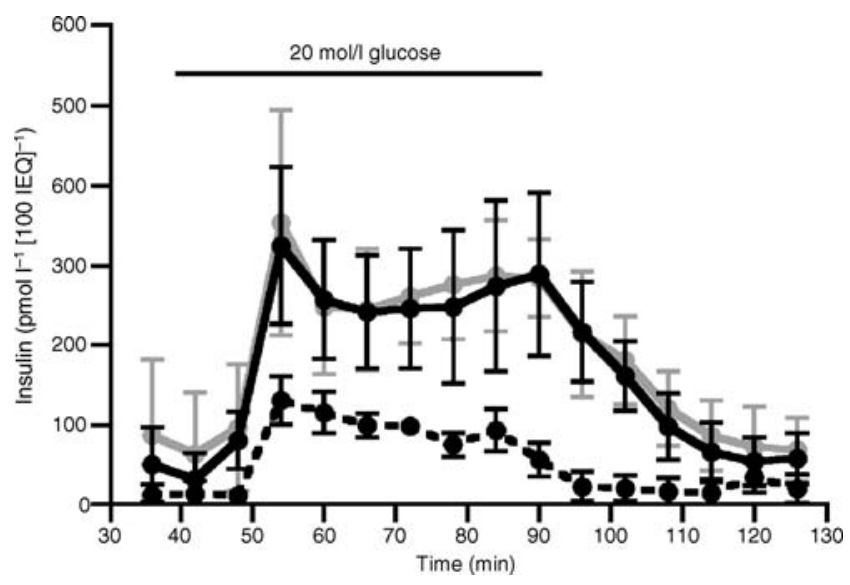

Fig. 3 Effect of LXR agonist on insulin secretion from human pancreatic islets. Islets were treated with LXR agonist (GW3965), $1 \mu \mathrm{mol} / \mathrm{l}$, (black line), methylprednisolone, $1 \mu \mathrm{g} / \mathrm{ml}$, (dotted line) or vehicle (grey line) for $24 \mathrm{~h}$. Twenty islets were hand picked, photographed and subjected to dynamic glucose challenge as described in the methods section. Insulin was measured with EIA and normalised to islet area using Cellimage. $n=6$ islets picked from pure fractions (90-95\% purity) originating from three independent donors. Data represent the mean \pm SEM. IEQ, islet equivalents a
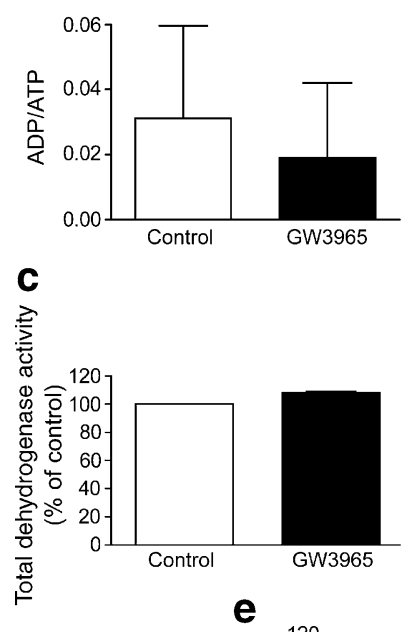

b

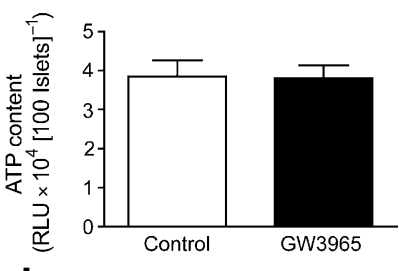

d
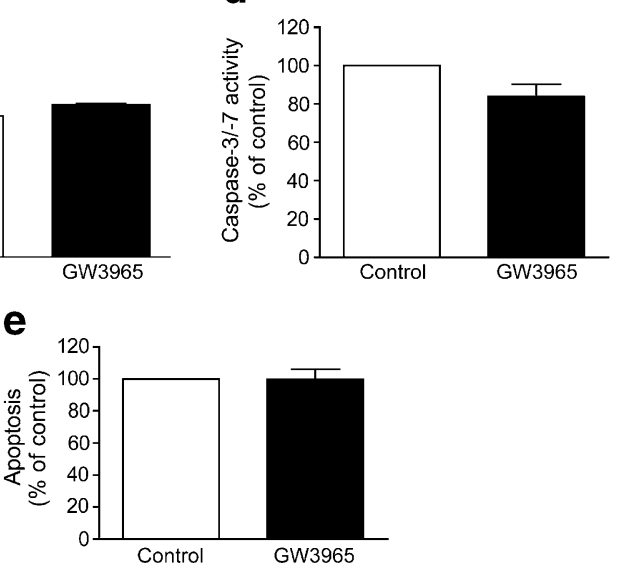

Fig. 4 Effect of LXR agonist on human islet viability. Islets were treated with LXR agonist (GW3965, black bars), $1 \mu \mathrm{mol} / 1$, or vehicle (control, white bars) for $24 \mathrm{~h}$ and subjected to analysis as described in the method section. a ADP/ATP ratio measured using the ApoGlow kit. b ATP content in islet lysates measured by a CellTiter-Glo bioassay. c Total dehydrogenase activity (XTT assay). d Caspase-3/-7 activity measured by the Apo-ONE caspase assay. e Apoptotic cell death measured by Cell Death Detection ELISA ${ }^{\text {PLUS }}$. Data are calculated as percentages of control and are presented as mean \pm SEM. $n=10$ fractions from five independent donors, with purity ranging from $50 \%$ to $95 \%$. RLU, relative luminescence units

effect of GW3965 has not been tested. We therefore treated human islets with GW3965, methylprednisolone or vehicle for $24 \mathrm{~h}$ and tested the insulin secretory response in a dynamic assay (Fig. 3). No difference in the shape, maximal insulin peak or AUC insulin could be detected between islets treated with GW3965 $(1 \mu \mathrm{mol} / \mathrm{l})$ or with vehicle (Fig. 3 and data not shown). However, when calculating insulin stimulation index (defined as the ratio of secreted insulin at $1.67 \mathrm{mmol} / \mathrm{l}$ glucose to secreted insulin at $20.0 \mathrm{mmol} / \mathrm{l}$ glucose), the index for GW3965treated islets was slighter higher than that for control islets (5.6 vs $4.5, p<0.05$ ), reflecting a tendency towards lower basal insulin secretion. As expected, islets treated with GW3965 and control islets had larger maximal insulin peaks, AUC insulin values and insulin stimulation indices compared with islets treated with methylprednisolone $(1 \mu \mathrm{g} / \mathrm{ml})$ (Fig. 3 and data not shown).

These data indicate that the LXR agonist GW3965 does not have negative effects on insulin secretion from human islets. 
Effects of GW3965 on human islet viability

As high dosages of LXR agonists have been shown to adversely affect murine islet viability [30], we evaluated the effect of LXR activation on human islet viability using different methods. As shown in Fig. 4a-e, in human islets none of the following was adversely affected by GW3965 (1 $\mu \mathrm{mol} / \mathrm{l}$ ) treatment for $24 \mathrm{~h}$ : (1) ADP:ATP ratio; (2) ATP content; (3) total dehydrogenase activity; (4) caspase-3 and -7 activity; (5) or apoptosis. Taken together, these data indicate that the concentration of GW3965 used in the present study does not affect human islet viability.

\section{Discussion}

Acute and chronic loss of islet function due to inflammatory processes (reviewed in [31]) is one of the main problems in clinical islet transplantation. Islets are usually cultured for 24-48 h prior to transplantation, and during this time period, modification of the islet inflammatory profile represents a possible strategy for improving islet function post-transplant $[32,33]$. Liver $X$ receptors are activated by endogenously produced oxysterols, and synthetic compounds such as T0901317 and GW3965 [34] have emerged as important regulators of inflammation [35]. We chose the selective LXR agonist GW3965 to explore its effects on the inflammatory status of human islets in vitro.

First, we showed that both LXR- $\alpha$ and $-\beta$ are produced in human islets. This is in agreement with previous studies showing that human and rodent islets produce both the LXR- $\alpha$ and LXR- $\beta$ isoforms [36]. We found that the production of LXRs was upregulated by LPS stimulation (Fig. 1a, b), suggesting that activation of LXRs during stress constitutes an endogenous protective mechanism in human islets, as has been found to be the case in macrophages [13] and human monocytes [12]. Adding GW3965 to LPS-stimulated human islets further upregulated the levels of LXRs (Fig. 1a, b). In agreement with our findings, the study by Meng et al. also showed a significant upregulation of LXRs by the addition of LXR agonists to mouse beta cells [37]. Furthermore, we showed that GW3965 significantly induced the expression of the typical LXR lipogenic target gene, $S R E B P-1 c$, as well as the cholesterol efflux genes $A B C A 1$ and $A B C G 1$ in LPSstimulated islets (Fig. 1c). As prolonged activation of lipogenic gene expression can result in accumulation of NEFA and triacylglycerols, causing beta cell dysfunction [38], we measured the total lipid accumulation as well as intracellular triacylglycerols and cholesterols in GW3965exposed islets. In our study, however, we found no evidence of storage of excess lipids in GW3965-exposed islets (Fig. 1d, e), and consequently no adverse effects on islet viability (Fig. 4a-e). It has been established that LXR is important for maintaining normal beta cell function [39], but compelling evidence has shown that abnormal activation of LXR could also induce islet lipotoxicity [30, 40]. A possible explanation may be the LXR agonist used (GW3965 in our study, T0901317 in the studies by Wente et al. [40] and Choe et al. [30]), as T0901317 has also been shown to be a potent pregnane $\mathrm{X}$ receptor ligand [41]. A second explanation may be the concentrations and/or exposure time used in the experiments, as we used both a relatively modest concentration and a relatively short incubation time $(24 \mathrm{~h})$. A third explanation for the diverging results may be the glucose concentrations used in the experiments $(5 \mathrm{mmol} / \mathrm{l}$ glucose in our experiment, $11.2 \mathrm{mmol} / \mathrm{l}$ in the experiment conducted by Choe and coworkers). Consequently, Choe and co-workers enhanced the adverse LXR effects when increasing the glucose concentrations to $31.2 \mathrm{mmol} / 1$ in their work [30]. Finally, we cannot rule out species-specific differences in the effects of LXRs, as murine islets or murine insulinoma cells were used by Choe et al. [30] and Wente et al. [40] whereas human pancreatic islets were used in our experiment. Such species differences may apply to pancreatic islets [27, 37].

Pro-inflammatory cytokines produced by cells as part of the innate immune response that infiltrate transplanted islets have important implications for islet survival and function after transplantation [42]. No studies to date have investigated the effects of LXR activation in human islets with focus on the inflammatory status. Using TLDA we obtained gene expression profiles for $47+1(G A P D H)$ anti- and proinflammatory markers, as well as markers associated with islet viability and insulin synthesis, to map the short-term effect of GW3965 on LPS-stimulated human islets. We observed a significant decrease of the mRNA expression of the pro-inflammatory mediators IL-8, MCP-1 and chemokine (C-C motif) ligand 5 (RANTES) (Table 2). Moreover, because TF is also thought to play an important role in the clinical outcome after islet transplantation [43], we included TF in addition to MCP-1 and IL- 8 in the subsequent analysis of pro-inflammatory mediators in human islets in response to GW3965 under normal conditions and after LPS stimulation using real-time qRT-PCR and EIA as detailed in the methods section. We found that mRNA expression of $T F, M C P-1$ and IL8 was significantly reduced, as were the amounts of the proteins produced in response to LXR activation (Fig. 2a-f). These data suggest that the local inflammatory response in human islets is lowered by short-term LXR activation.

Interestingly, the TLDA data also showed significant upregulation of two known pro-angiogenic factors ANGPT1 and VEGF in GW3965-exposed islets (Table 2). These factors have been shown to promote graft angiogenesis and enhance islet revascularisation, contributing to 
improved glycaemic control and better preservation of islet mass in mice [44, 45]. Moreover, we also found that LXR activation significantly decreased the transcription factor STAT-1, known to be involved in cytokine-induced beta cell death [46]. On the other hand we observed upregulation of TLR4, a receptor associated with enhanced bacterial removal during infection. These data suggest that the endogenous effects of LXRs also apply to human islets, on one hand limiting excessive cytokine production and on the other hand enhancing removal of gram-negative bacteria during infection (reviewed in [47]). However, TLR4 has also been implicated in beta cell death and graft rejection after transplantation [48]. The role of these mediators in the recruitment of inflammatory cells and angiogenesis in islets warrants further studies.

To evaluate islet viability, we measured insulin secretion from islets exposed to GW3965 and vehicle in a dynamic model. No difference in net insulin secretion or maximal insulin peaks could be detected (Fig. 3). However, there was a tendency towards lower basal insulin secretion, resulting in an increased insulin stimulation index. Increased basal insulin secretion is associated with cytokineinduced islet dysfunction [49], and these data may imply that GW3965-induced reduction in inflammatory milieu has positive effects on human islets in vitro. We also evaluated the effect of GW3965 on mitochondrial dehydrogenase and caspase-3 and -7 activities as well as apoptosis, and found no adverse effects of GW3965 (Fig. 4c-e).

Taken together, the data obtained in this study show that short-term $(24 \mathrm{~h})$ activation of LXRs with the synthetic LXR agonist GW3965 has potent dampening effects on key inflammatory mediators in human islets in vitro without any adverse effect on insulin secretion or viability. Although we have recently shown a potent antiinflammatory effect by glucocorticoids added to human islets in vitro [27], the gold-standard immunosuppressive regimen in islet transplantation is glucocorticoid-free because of the diabetogenic effects of glucocorticoids [50]. This prompts the search for alternative antiinflammatory strategies. Our data suggest a possible role for GW3965 as an anti-inflammatory agent in human islet culture prior to transplantation, and may represent a strategy to increase islet suitability for transplantation. However, lipotoxicity remains a concern, especially with high glucose concentrations and/or prolonged vigorous LXR stimulation. Even though LXR agonists hold promise in islet transplantation, the effects must be verified in vivo.

Acknowledgements This study was supported by grants from the Norwegian Research Council (175462/V50), Medinnova AS, Helse SØR RHF (3b-170) and The Norwegian Diabetes Association. The authors are grateful to members of the Nordic Network for Islet
Transplantation. Human monocytes were a gift from J. Ågren. The technical assistance of A. Friberg, B. Halvorsen and M. Brunvand is gratefully acknowledged.

Duality of interest J. L. Collins is an employee of GlaxoSmithKline.

\section{References}

1. Ryan EA, Paty BW, Senior PA et al (2005) Five-year follow-up after clinical islet transplantation. Diabetes 54:2060-2069

2. Contreras JL, Eckstein C, Smyth CA et al (2003) Brain death significantly reduces isolated pancreatic islet yields and functionality in vitro and in vivo after transplantation in rats. Diabetes 52:2935-2942

3. Korsgren O, Lundgren T, Felldin M et al (2008) Optimising islet engraftment is critical for successful clinical islet transplantation. Diabetologia 51:227-232

4. Ko SH, Ryu GR, Kim S et al (2008) Inducible nitric oxide synthase-nitric oxide plays an important role in acute and severe hypoxic injury to pancreatic beta cells. Transplantation 85:323-330

5. Barshes NR, Wyllie S, Goss JA (2005) Inflammation-mediated dysfunction and apoptosis in pancreatic islet transplantation: implications for intrahepatic grafts. J Leukoc Biol 77:587-597

6. Bensinger SJ, Tontonoz P (2008) Integration of metabolism and inflammation by lipid-activated nuclear receptors. Nature 454:470-477

7. Bradley MN, Hong C, Chen M et al (2007) Ligand activation of LXR beta reverses atherosclerosis and cellular cholesterol overload in mice lacking LXR alpha and apoE. J Clin Invest 117:2337-2346

8. Riddell DR, Zhou H, Comery TA et al (2007) The LXR agonist TO901317 selectively lowers hippocampal Abeta42 and improves memory in the Tg2576 mouse model of Alzheimer's disease. Mol Cell Neurosci 34:621-628

9. Morales JR, Ballesteros I, Deniz JM et al (2008) Activation of liver $\mathrm{X}$ receptors promotes neuroprotection and reduces brain inflammation in experimental stroke. Circulation 118:1450-1459

10. Castrillo A, Joseph SB, Marathe C, Mangelsdorf DJ, Tontonoz P (2003) Liver X receptor-dependent repression of matrix metalloproteinase-9 expression in macrophages. J Biol Chem 278:10443-10449

11. Zhang-Gandhi CX, Drew PD (2007) Liver X receptor and retinoid $\mathrm{X}$ receptor agonists inhibit inflammatory responses of microglia and astrocytes. J Neuroimmunol 183:50-59

12. Myhre AE, Agren J, Dahle MK et al (2008) Liver X receptor is a key regulator of cytokine release in human monocytes. Shock $29: 468-474$

13. Terasaka N, Hiroshima A, Ariga A et al (2005) Liver X receptor agonists inhibit tissue factor expression in macrophages. FEBS J 272:1546-1556

14. Wang YY, Dahle MK, Agren J et al (2006) Activation of the liver $\mathrm{X}$ receptor protects against hepatic injury in endotoxemia by suppressing Kupffer cell activation. Shock 25:141-146

15. Bennet W, Groth CG, Larsson R, Nilsson B, Korsgren O (2000) Isolated human islets trigger an instant blood mediated inflammatory reaction: implications for intraportal islet transplantation as a treatment for patients with type 1 diabetes. Ups J Med Sci 105:125-133

16. Johansson M, Lukinius A, Moberg L et al (2005) Tissue factor produced by the endocrine cells of the islets of Langerhans is associated with a negative outcome of clinical islet transplantation. Diabetes 54:1755-1762

17. Korsgren O, Nilsson B, Berne C et al (2005) Current status of clinical islet transplantation. Transplantation 79:1289-1293 
18. Collins JL, Fivush AM, Watson MA et al (2002) Identification of a nonsteroidal liver $\mathrm{X}$ receptor agonist through parallel array synthesis of tertiary amines. J Med Chem 45:1963-1966

19. Goto M, Eich TM, Felldin M et al (2004) Refinement of the automated method for human islet isolation and presentation of a closed system for in vitro islet culture. Transplantation 78:13671375

20. Goto M, Holgersson J, Kumagai-Braesch M, Korsgren O (2006) The ADP/ATP ratio: A novel predictive assay for quality assessment of isolated pancreatic islets. Am J Transplant 6:24832487

21. Cummins CL, Volle DH, Zhang Y et al (2006) Liver X receptors regulate adrenal cholesterol balance. J Clin Invest 116:1902-1912

22. Chisholm JW, Hong J, Mills SA, Lawn RM (2003) The LXR ligand T0901317 induces severe lipogenesis in the $\mathrm{db} / \mathrm{db}$ diabetic mouse. J Lipid Res 44:2039-2048

23. Fontaine C, Rigamonti E, Nohara A et al (2007) Liver X receptor activation potentiates the lipopolysaccharide response in human macrophages. Circ Res 101:40-49

24. Berg AK, Korsgren O, Frisk G (2006) Induction of the chemokine interferon-gamma-inducible protein-10 in human pancreatic islets during enterovirus infection. Diabetologia 49:2697-2703

25. Gyulkhandanyan AV, Lee SC, Bikopoulos G, Dai F, Wheeler MB (2006) The Zn2+-transporting pathways in pancreatic beta-cells: a role for the L-type voltage-gated $\mathrm{Ca} 2+$ channel. J Biol Chem 281:9361-9372

26. Piemonti L, Leone BE, Nano R et al (2002) Human pancreatic islets produce and secrete MCP-1/CCL2: relevance in human islet transplantation. Diabetes 51:55-65

27. Lund T, Fosby B, Korsgren O, Scholz H, Foss A (2008) Glucocorticoids reduce pro-inflammatory cytokines and tissue factor in vitro and improve function of transplanted human islets in vivo. Transpl Int 21:669-678

28. Redmon JB, Olson LK, Armstrong MB, Greene MJ, Robertson RP (1996) Effects of tacrolimus (FK506) on human insulin gene expression, insulin mRNA levels, and insulin secretion in HITT15 cells. J Clin Invest 98:2786-2793

29. Hjelmesaeth J, Hagen LT, Asberg A et al (2007) The impact of short-term ciclosporin A treatment on insulin secretion and insulin sensitivity in man. Nephrol Dial Transplant 22:1743-1749

30. Choe SS, Choi AH, Lee JW et al (2007) Chronic activation of liver $\mathrm{X}$ receptor induces beta-cell apoptosis through hyperactivation of lipogenesis: liver $\mathrm{X}$ receptor-mediated lipotoxicity in pancreatic beta-cells. Diabetes 56:1534-1543

31. Huang X, Moore DJ, Ketchum RJ et al (2008) Resolving the conundrum of islet transplantation by linking metabolic dysregulation, inflammation, and immune regulation. Endocr Rev 29:603-630

32. Lewis EC, Shapiro L, Bowers OJ, Dinarello CA (2005) Alpha1antitrypsin monotherapy prolongs islet allograft survival in mice. Proc Natl Acad Sci U S A 102:12153-12158

33. Yang Z, Chen M, Ellett JD et al (2005) Inflammatory blockade improves human pancreatic islet function and viability. Am J Transplant 5:475-483
34. Chen W, Chen G, Head DL, Mangelsdorf DJ, Russell DW (2007) Enzymatic reduction of oxysterols impairs LXR signaling in cultured cells and the livers of mice. Cell Metab 5:73-79

35. Joseph SB, Castrillo A, Laffitte BA, Mangelsdorf DJ, Tontonoz P (2003) Reciprocal regulation of inflammation and lipid metabolism by liver X receptors. Nat Med 9:213-219

36. Efanov AM, Sewing S, Bokvist K, Gromada J (2004) Liver X receptor activation stimulates insulin secretion via modulation of glucose and lipid metabolism in pancreatic beta-cells. Diabetes 53 (Suppl 3):S75-78

37. Meng ZX, Nie J, Ling JJ et al (2009) Activation of liver X receptors inhibits pancreatic islet beta cell proliferation through cell cycle arrest. Diabetologia 52:125-135

38. Wang H, Maechler P, Antinozzi PA et al (2003) The transcription factor SREBP-1c is instrumental in the development of beta-cell dysfunction. J Biol Chem 278:16622-16629

39. Gerin I, Dolinsky VW, Shackman JG et al (2005) LXRbeta is required for adipocyte growth, glucose homeostasis, and beta cell function. J Biol Chem 280:23024-23031

40. Wente W, Brenner MB, Zitzer H, Gromada J, Efanov AM (2007) Activation of liver $\mathrm{X}$ receptors and retinoid $\mathrm{X}$ receptors induces growth arrest and apoptosis in insulin-secreting cells. Endocrinology 148:1843-1849

41. Mitro N, Vargas L, Romeo R, Koder A, Saez E (2007) T0901317 is a potent PXR ligand: implications for the biology ascribed to LXR. FEBS Lett 581:1721-1726

42. Johansson U, Olsson A, Gabrielsson S, Nilsson B, Korsgren O (2003) Inflammatory mediators expressed in human islets of Langerhans: implications for islet transplantation. Biochem Biophys Res Commun 308:474-479

43. Bertuzzi F, Marzorati S, Maffi P et al (2004) Tissue factor and CCL2/monocyte chemoattractant protein-1 released by human islets affect islet engraftment in type 1 diabetic recipients. J Clin Endocrinol Metab 89:5724-5728

44. Zhang N, Richter A, Suriawinata J et al (2004) Elevated vascular endothelial growth factor production in islets improves islet graft vascularization. Diabetes 53:963-970

45. Su D, Zhang N, He J et al (2007) Angiopoietin-1 production in islets improves islet engraftment and protects islets from cytokineinduced apoptosis. Diabetes 56:2274-2283

46. Gysemans CA, Ladriere L, Callewaert H et al (2005) Disruption of the gamma-interferon signaling pathway at the level of signal transducer and activator of transcription-1 prevents immune destruction of beta-cells. Diabetes 54:2396-2403

47. Valledor AF (2005) The innate immune response under the control of the LXR pathway. Immunobiology 210:127-132

48. Goldberg A, Parolini M, Chin BY et al (2007) Toll-like receptor 4 suppression leads to islet allograft survival. FASEB J 21:2840-2848

49. Polastri L, Galbiati F, Bertuzzi F et al (2002) Secretory defects induced by immunosuppressive agents on human pancreatic betacells. Acta Diabetol 39:229-233

50. Shapiro AM, Ricordi C, Hering BJ et al (2006) International trial of the Edmonton protocol for islet transplantation. N Engl J Med $355: 1318-1330$ 